\title{
KAJI EKSPERIMENTAL COLD DAN HOT EGR DENGAN BAHAN BAKAR CAMPURAN BIODIESEL TERHADAP EFISIENSI THERMAL MESIN DIESEL
}

\author{
Eka Darmana \\ Jurusan Teknika, Akademi Pelayaran Niaga Indonesia \\ J1. Pawiyatan Luhur II/17, Bendan Dhuwur, Semarang. \\ Email: ekadarmana@yahoo.com
}

\begin{abstract}
Abstrak
Cadangan bahan bakar fosil semakin menipis akibat pemakaian mesin berbahan bakar fosil semakin meluas. Diperlukan alternatif bahan bakar yang dapat diperbarui, salah satunya adalah biodiesel yang berasal dari minyak jarak (jatropha). Pemakaian jatropha sebagai bahan bakar mesin diesel tetap menghasilkan emisi Nox, maka diperlukan adanya sistem yang mereduksi Nox, salah satunya dengan mensirkulasikan gas buang (EGR) kedalam dilinder. Bahan bakar jatropha dengan sistem EGR juga mempengarui efisiensi dari mesin diesel, maka diperlukan banyak kajian. Dalam kajian ini dilakukan eksperimen untuk mengetahui brake thermal efficiency mesin diesel ketika menggunakan bahan bakar campuran jatropha dengan di pasang cold maupun Hot EGR. Eksperimen dilakukan pada mesin diesel dengan memvariasi beban pada putaran konstan 2000 rpm. Masing-masing variasi beban diuji dengan memvariasi laju EGR untuk bahan bakar diesel fuel (D100) dan campuran jatropha 30\% (D70J30). Hasil kajian menunjukkan bahwa BSFC paling rendah 0,21 kg/kWh ketika dioperasikan dengan bahan bakar campuran jatropha terdapat pada laju Cold EGR 14,1\% pada beban diatas 50\%. Brake thermal efficiency mengalami kenaikan mencapai 40,5\% ketika dioperasikan dengan Cold EGR menggunakan bahan bakar campuran jatropha 30\% (D70J30). Laju EGR yang optimal pada angka 14,1\%.
\end{abstract}

Kata kunci: cold dan Hot EGR, jatropha, brake thermal efficincy, BFSC

\section{Pendahuluan}

Efek dari pemakaian mesin diesel di berbagai bidang, baik transportasi (kapal, bus, truk, kendaraan pribadi) maupun industri telah menaikkan kebutuhan bahan bakar yang berasal dari fosil dan tidak dapat diperbarui dalam waktu pendek. Hal ini akan berdampak pada cadangan bahan bakar fosil tersebut semakin menipis. Data dari ditjen migas menunjukkan bahwa tahun demi tahun produksi bahan bakar minyak mengalami penurunan sementara konsumsi bakan bakar minyak mengalami kenaikan yang signifikan. Pemerintah telah mengambil kebijakan untuk mengantisipasi kemungkinan krisis energi yang akan melanda Indonesia yaitu dengan mengeluarkan peraturan presiden republik indonesia nomor 5 tahun 2006 tentang kebijakan energi nasional. Peraturan ini menjadi pegangan untuk mencari solusi dalam mengatasi kemungkinan krisis energi yang akan melanda Indonesia. Salah satu solusi untuk menghadapi krisis energy tersebut adalah dengan menggalakkan pemakaian bahan bakar yang dapat diperbaruhi. Salah satu bahan bakar untuk mesin diesel yang dapat diperbaruhi adalah biodiesel dari tanaman jarak (jatropha). Jatropha dapat menjadi alternatif pengganti bahan bakar diesel dan menghasilkan efisiensi yang lebih besar dibandingkan diesel fuel akan tetapi memiliki kekurangan yang signifikan yaitu memicu terbentuknya Nox (Gomaa M., 2011).

Tidak dipungkiri bahwa penyakit mesin diesel adalah terbentuknya asap tebal maupun terbentuknya nilai Nox. Perkembangan teknologi memungkinkan untuk mengurangi nilai Nox yang diproduksi oleh mesin diesel. Salah satu tehnik efektif untuk mengurangi emisi gas buang yang diproduksi oleh mesin diesel adalah mengembalikan sebagian kecil gas buang ke dalam silinder atau exhaust gas recirculation (EGR) (Rajan K., 2009). Perkembangan ilmu dan pengetahuan membagi sistem EGR berdasarkan temperaturnya menjadi dua yaitu Hot EGR dan Cold EGR.

Penggunaan sistem EGR telah terbukti mengurangi permasalahan tentang NOx yang 
ditimbulkan oleh mesin diesel, akan tetapi masih sangat diperlukan pengkajian efek dari penggunaan EGR terhadap performa mesin diesel dengan menggunakan campuran jatropha sebagai bahan bakar. Maka dalam kajian ini digunakan Hot EGR dan Cold EGR untuk mengetahui performa dari mesin diesel apabila menggunakan bahan bakar campuran jatropha dan diesel fuel.

\section{Exhaust Gas Recirculation (EGR)}

Exhaust gas recirculation (EGR) merupakan suatu tehnik yang mencirkulasikan sebagian kecil gas buang kedalam silinder bercampur dengan udaran pembakaran. Tehnik EGR telah teruji dapat mengurangi emisi gas buang terutama Nitrogen oksida (NOx). Rajan dan Senthil Kumar (2009), menyimpulkan bahwa EGR dapat mengurangi kadar emisi NOx, karena terdapat muatan air pada udara masukan, sehingga menurunkan suhu pembakaran. Suhu pembakaran yang rendah akan menyebabkan pembentukan jelaga yang meningkat. Sehingga memakaian EGR akan membentuk trade-off antara penurunan emisi NOx dan peningkatan emisi jelaga, $\mathrm{CO}$ dan HC. Saat ini EGR diklasifikasikan menjadi dua yaitu EGR yang dijaga suhunya agar tetap tinggi (Hot EGR) dan EGR yang dilewatkan pendinginan di heat exchanger (Cold EGR). Adanya Hot EGR mengakibatkan naiknya temperatur udara bilas yang masuk kedalam ruang bakar sementara Cold EGR mengakibatkan menurunnya temperatur udara bilas yang masuk kedalam ruang bakar dan akan mempengaruhi pembakaran didalamnya. Niranjan L. (2006) menyatakan bahwa sistem cold EGR lebih efektif dibandingkan dengan hot EGR dalam mereduksi emisi NOx. Hauntalas D. T. dkk. (2008) juga menyatakan bahwa penurunan temperatur EGR berdampak positif terhadap BSFC dan soot. Jumlah exhaust gas recirculation yang masuk ke dalam ruang bakar dapat dihitung berdasarkan persamaan berikut:
$\% \mathrm{EGR}=\frac{\dot{m}_{E G R}}{\dot{m}_{i}} \times 100 \% \quad($ Heywood, 1988)

Dimana :

$\dot{\mathrm{m}}_{E G R}=$ laju aliran massa gas yang sirkulasikan ke silinder

$\dot{\mathrm{m}}_{\mathrm{i}} \quad=$ laju aliran massa udara total yang masuk ke silinder

\section{Metode Eksperimen}

Spesifikasi mesin diesel yang digunakan untuk eksperimen sebagaimana ditunjukkan pada tabel 1. Skema peralatan eksperimen ditunjukkan pada gambar 1. Pengujian dilakukan pada putaran yang konstan yaitu $2000 \mathrm{rpm}$ dengan pembebanan 25\%, 50\%, $75 \%$ dan $100 \%$. Dari masing masing variasi pembebanan diambil data dengan memvariasi laju aliran EGR dan variasi bahan bakar. Variasi bahan bakar yang diuji adalah diesel fuel dan campuran jatropha $30 \%$. Spesifikasi bahan bakar ditunjukkan pada gambar 2 .

\section{Tabel 1. Spesifikasi mesin uji}

\begin{tabular}{|l|l|}
\hline Tipe Motor & $\begin{array}{l}\text { Diesel 4 silinder direct } \\
\text { injection } \\
\text { Diameter/stroke }\end{array}$ \\
$\begin{array}{l}93 \mathrm{~mm} / 102 \mathrm{~mm} \\
\text { Torsi maks. }\end{array}$ \\
Daya maks. & $52 / 3000(\mathrm{~kW} / \mathrm{rpm})$ \\
Rasio kompresi & $18,2: 1$ \\
\hline
\end{tabular}

\section{Tabel 2. Spesifikasi bahan bakar}

(Darmana Eka, 2017)

\begin{tabular}{|l|l|l|}
\hline \multicolumn{1}{|c|}{ Karakteristik } & D100 & Jatropha \\
\hline Angka Setana & 48,0 & 41,8 \\
Nilai Kalor (MJ/kg) & 45,21 & 37,97 \\
Viscositas pada Suhu & 2,5 & 3,67 \\
$40^{\circ} \mathrm{C}\left(\mathrm{mm}^{2} / \mathrm{s}\right)$ & & \\
Density pada temperatur & 0,84 & 0,918 \\
$15^{\circ} \mathrm{C}\left(\mathrm{gr} / \mathrm{cm}^{3}\right)$ & & \\
Titik Nyala $\left({ }^{\circ} \mathrm{C}\right)$ & 60,0 & 198,0 \\
Kadar Air $(\% \mathrm{v})$ & 0,05 & 3,16 \\
\hline
\end{tabular}




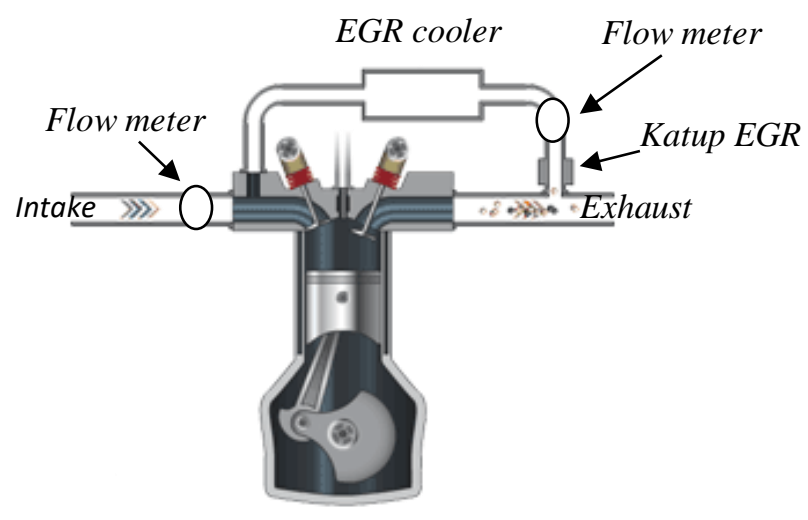

a. Cold EGR

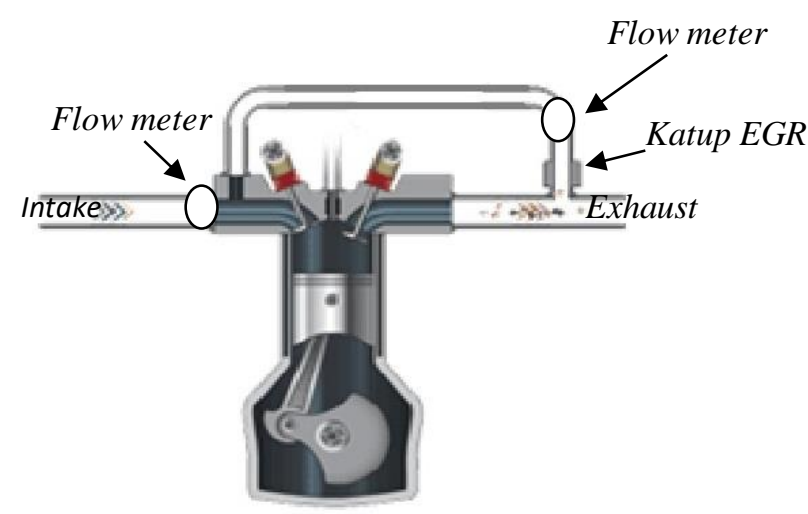

b. Hot EGR

\section{Gambar 1. Skema peralatan eksperimen}

\section{Hasil Dan Pembahasan}

\subsection{Pengaruh EGR terhadap BSFC.}

Gambar 2 menunjukkan hubungan antara jumah laju EGR terhadap BSFC pada berbagai variasi pembebanan dengan menggunakan diesel fuel. Sedangkan gambar 3 menunjukkan hubungan antara jumlah laju EGR terhadap BSFC ada berbagai variasi pembebanan dengan menggunakan campuran jatropha $30 \%$. Dari Hasil pengujian menunjukkan bahwa pada berbagai tingkat pembebanan, terjadi peningkatan BSFC yang signifikan di berbagai tingkat laju EGR. Ketika menggunakan bahan bakar diesel fuel (D100) peningkatan BSFC terjadi seiring di tambahkan EGR kedalam silinder. Peningktan BSFC semakin tampak pada beban di atas 50\%. Dari masing-masing variasi laju EGR (12,8\% - 16,5\%) terlihat BSFC Cold EGR cenderung lebih tinggi dibandingkan $\mathrm{Hot}$ $E G R$. Hal ini kemungkinan adanya carbon dioksida yang bercampur dengan udara bilas yang merupakan bawaan dari EGR. Sehingga menjadikan pembakaran yang kurang sempurna, dengan kata lain untuk mengangkat beban yang sama maka butuh bahan bakar yang lebih ketika dipasang sistem EGR (Rajan K. dan Senthil Kumar, 2009).

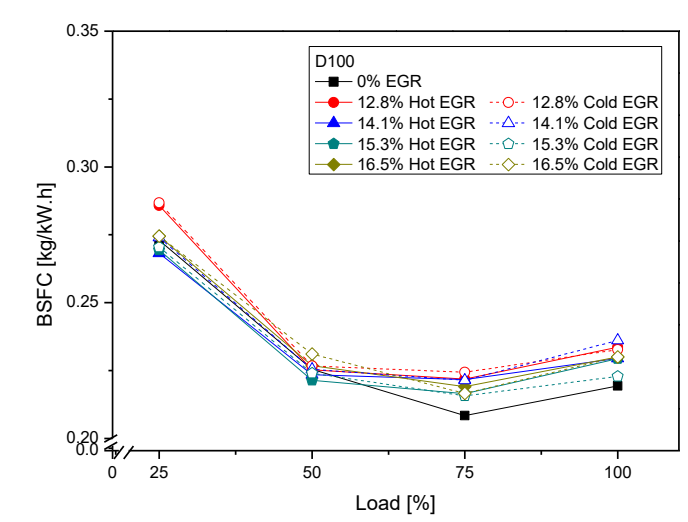

\section{Gambar 2. Grafik hubungan laju EGR terhadap BSFCberbagai beban Menggunakan bahan bakar diesel fuel}

Hal serupa terjadi ketika diesel fuel di campur dengan jatropa 30\% (D70J30). Terjadi peningkatan BSFC yang signifikan ketika menggunakan sistem Hot EGR maupun Cold $E G R$ di semua semua variasi pembebanan. Peningkatan BSFC Hot EGR lebih tinggi dibandingkan dengan sistem Cold EGR. Hal ini kemungkinan pengaruh dari density udara bilas lebih kecil ketika menggunakan $\mathrm{Hot}$ $E G R$ dibandingkan dengan menggunakan Cold EGR. Efeknya masa udara yang masuk ke dalam silinder lebih sedikit dan mengurangi kesempurnaan pembakaran. Sehingga untuk bertahan pada daya ataupun beban yang sama dibutuhkan bahan bakar yang lebih banyak.

Peningkatan BSFC juga terlihat ketika dioperasikan dengan bahan bakar yang berbeda. Penggunakan bahan bakar campuran jatropha berpotensi menaikkan BFSC dibandingkan menggunakan bahan bakar diesel fuel pada pada tingkat laju EGR yang sama. Peningkatan BFSC tersebut bisa terlihat pada semua pembebanan. 


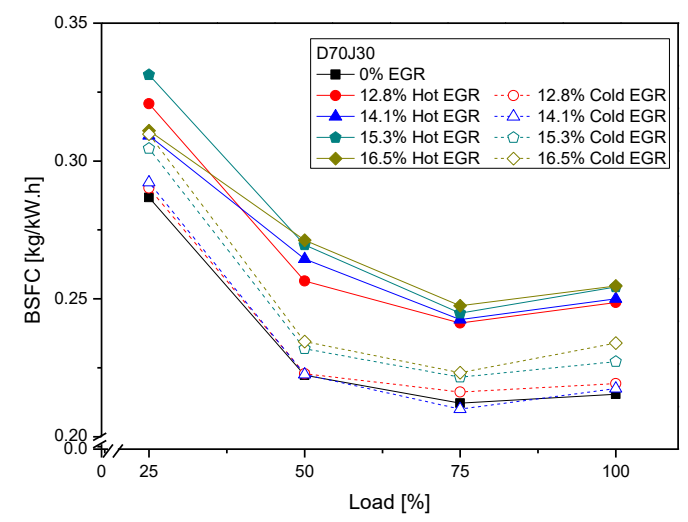

\section{Gambar 3. Grafik hubungan laju EGR terhadap BSFC berbagai beban menggunakan bahan bakar campuran diesel fuel dengan jatropha $30 \%$}

Hal ini kemungkinan dikarenakan nilai kalor jatropha lebih kecil dibandingkan nilai kalor diesel fuel sehingga membutuhkan bahan bakar yang lebih banyak untuk mempertahankan beban yang sama. Ditunjukkan pada gambar 2 dan gambar 3 bahwa penggunaan Cold EGR menunjukkan BSFC yang lebih kecil dibandingkan Hot $E G R$. Dan pada hasil pengujian menunjukkan bahwa laju EGR yang paling optimal berkisar $14,1 \%$

\subsection{Pengaruh EGR terhadap brake thermal efficiency}

Brake thermal efficiency (BTE) meningkat seiring dengan meningkatnya beban ketika di pasang sistem EGR dengan menggunakan bahan bakar diesel fuel (D100). BTE optimal terletak pada beban $75 \%$. Akan tetapi jika dibandingkan dengan non EGR terdapat penurunan BTE terutama pada beban diatas $50 \%$ sbagaimana yang dinjukkan pada gambar 4. Penurunan ini dapat disebabkan oleh kandungan oksigen pada udara bilas yang berkurang digantikan oleh gas buang yang disirkulasikan, sehingga pembakaran kurang sempurna (Anivash K. dkk., 2004). Penggunaan cold dan Hot EGR pada bahan bakar diesel fuel menunjukkan tendensi yang sama, BTE tertinggi terdapat pada laju EGR $15,3 \%$.

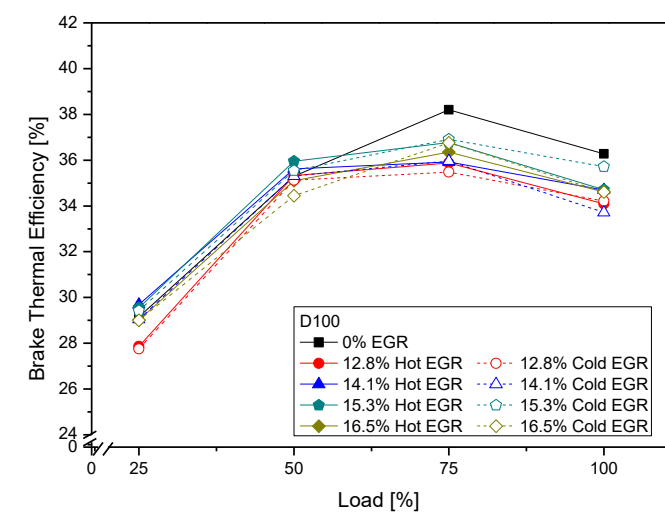

\section{Gambar 4. Grafik hubungan laju EGR terhadap BTE berbagai beban menggunakan bahan bakar diesel fuel}

Pada gambar 5 Menunjuukkan hubungan laju EGR dengan BTE menggunakan bahan bakar canmpuran jatropha 30\% (D70J30). Dari grafik tersebut terlihat bahwa BTE meningkat seiring dengan meningkatnya beban mesin dan puncak BTE terletak pada beban $75 \%$. Sementara itu BTE mengalami penurunan dengan digunakannya sistem EGR. Ini dapat disebabkan oleh kandungan oksigen pada udara bilas berkurang karena sebagian digantikan oleh gas buang yang disirkulasikan kembali ke dalam silinder. Penggunaan Hot $E G R$ ternyata sangat signifikan menurunkan BTE, hal ini mungkin dikarenakan menurunnya density dari udara bilas karena bercampur dengan sebagian gas buang yang masih bersuhu tinggi. Efek dari density yang rendah menyebabkan masa udara yang masuk ke dalam silinder berkurang sehingga pembakaran kurang sempurna dan menurunkan BTE.

Penggunaan Hot EGR mengunakan variasi bahan bakar D100 dan D70J30 menunjukkan adanya penurunan BTE bahan bakar D70J30 jika dibandingkan dengan bahan bakar D100. BTE meningkat signifikan ketika dipasang dengan sistem Cold EGR. BTE mengunakan bahan bakar diesel fuel mampu mencapai $36 \%$ pada laju EGR 15\% dan beban $75 \%$. 


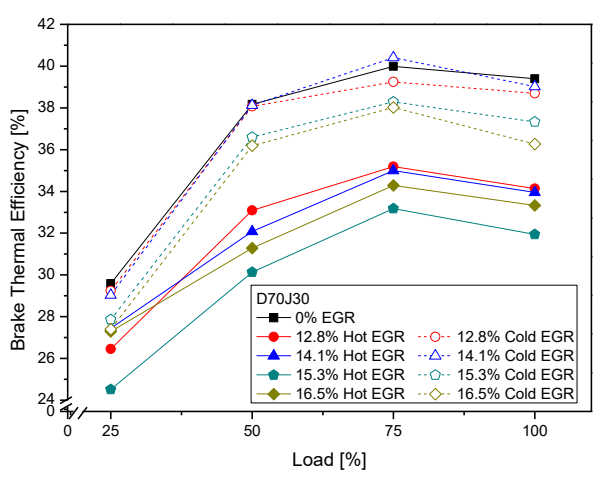

\section{Gambar 5. Grafik hubungan laju EGR terhadap BTE berbagai beban menggunakan bahan bakar campuran diesel fuel dengan jatropha $30 \%$}

Sementara itu, ketika menggunakan bahan bakar campuran jatropha peningkatan BTE mampu mencapai $40,5 \%$ pada laju EGR $14,1 \%$ dan beban $75 \%$ sebagaimana terlihat pada gambar 4 dan gambar 5. Hal ini dapat terjadi disebabkan density udara bilas meningkat efek dari pendinginan EGR sehingga masa udara bilas yang masuk ke dalam silinder lebih besar dan pembakaran lebi sempurna.

\section{Kesimpulan}

Berdasarkan hasil dan pembahasan diatas, eksperimental tentang pengaruh cold dan $\mathrm{Hot}$ EGR menggunakan bahan bakar diesel fuel dan campuran jatropha terhadap effisiensi thermal mesin diesel dapat disimpulkan antara lain sebagai berikut: a) BSFC pada mesin diesel berbahan bakar diesel fuel lebih kecil dibanding menggunakan bahan bakar campuran jatropha $30 \%$ dengan sistem Hot EGR maupun Cold EGR kecuali pada laju Cold EGR $14,1 \%$ pada beban diatas $50 \%$. Pada laju Cold EGR tersebut menunjukkan BSFC yang paling kecil yaitu sekitar 0,21 $\mathrm{kg} / \mathrm{kWh}$. b) Brake thermal efficiency mesin diesel berbahan bakar campuran jatropha mengalami peningkatan yang signifikan ketika di pasang sistem Cold EGR dibanding dengan Hot EGR. Peningkatan brake thermal efficiency tersebut mencapai $40,5 \%$.
Pengunaan bahan bakar diesel fuel dan campuran jatropha dengan sistem Hot EGR hanya mampu sekitar $35 \%$. Sehingga dapat disimpulkan bahwa penggunaan sistem Cold EGR lebih efektif dibanding Hot EGR pada mesin diesel berbahan bakar campran jatropha.

\section{Daftar Pustaka}

- Darmana Eka, 2017, Studi Eksperimental EGT dan Smoke Opacity Pada Mesin Diesel Menggunakan Bahan Bakar Campuran Jatropha Dengan Sistem Cold EGR, Eksergi, Vol.13, pp. 32 - 39.

- Gomaa, M., Alimin, A.J., Kamarudin, K.A., 2011, The effect of EGR rates on NOX and smoke emissions of an IDI diesel engine fuelled with Jatropha biodiesel blends, International Energy and Environment Foundation, vol. 2, pp. 477 - 49.

- Hauntalas, D.T., Mavropoulus, G.C., Binder, K.B., 2008, Effect of exhaust gas recirculation (EGR) temperature for various EGR rates on heavy duty DI diesel engine performance and emissions, Energy, vol. 33, pp. 272-286.

- Heywood, John B.L., 1988, Internal Combustion Engine Fundamentals, McGraw-Hill Inc., New York.

- Niranjan, L., Thomas, S., Sajith, V., 2006, Experimental investigation on the effects of cold and hot EGR using diesel and biodiesel as Fuel, international Conference on Energy and Environment, Universiti Tenaga Nasional, Malaysia.

- Peraturan Presiden Republik Indonesia Nomor 5., Tahun 2006, Tentang Kebijakan Energi Nasional.

- Pradeep, V., Sharma, R.P., 2007, Use of hot EGR for NOx control in a compression ignition engine fuelled with biodiesel from jatropha oil, Renewable Energy, vol. 32, pp. 1132-1154.

- Rajan, K., Senthil Kumar, 2009, The effect of exhaust gas recirculation (EGR) on the performance and emission characteristics of diesel engine with sunflower oil methyl ester, International Journal of Chemical Engineering Research. Vol. 1, pp. 31-39. 